\title{
UNA MIRADA AL CUENTO URUGUAYO CONTEMPORÁNEO: TRADUCCIÓN DE DOS CUENTOS DE INÉS BORTAGARAY
}

\author{
कोen \\ Helena Coimbra Meneghello \\ ROSARIO LÁZARO IGOA
}

\begin{abstract}
A la mesa
El mantel es blanco. Cubre todas las esquinas de esta larga mesa de madera puesta a lo largo del jardín, y llega a rozar el suelo. Sobre el mantel hay platos, fuentes, cucharas, cucharones, cuchillos, servilletas, tenedores, botellas, jarras, flores, migas de pan. Alrededor estamos nosotros, la familia unida. Todos sentados a lo largo de esta gran mesa que ocupa dos parcelas de quinta, la nuestra y la de los otros, los parientes. No somos tan ruidosos como una familia italiana ni se hace el gran escándalo ni el borracho da la nota, pero igual somos borrachos. Todos tomamos vino, por ejemplo. La mesa está rota, cortada en dos, pero nadie parece notarlo. En el medio la mesa se corta y unas astillas sobresalen del mantel, lo rasgan antes del ruedo, emergen como púas.

La mesa se corta en dos entre las dos parcelas. De un lado quedamos nosotros; del otro, los parientes.

La pequeña esposa de mi primo alto, el de boca mojada co-
\end{abstract}

\section{À mesa}

A toalha é branca. Cobre todas as esquinas desta comprida mesa de madeira posta no jardim, e chega a roçar o chão. Sobre a toalha há pratos, travessas, colheres, conchas, facas, guardanapos, garfos, garrafas, jarras, flores, miolo de pão. À volta estamos nós, a família unida. Todos sentados ao longo desta grande mesa que ocupa duas parcelas do sítio, a nossa e a dos outros, os parentes. Não somos tão barulhentos como uma família italiana nem se faz um grande escândalo nem o bêbado dá o tom, mas também somos bêbados. Todos tomamos vinho, por exemplo. A mesa está rachada, cortada em duas, mas ninguém parece notar. No meio a mesa se corta e umas felpas sobressaem da toalha, a rasgam antes da barra, emergem como puas.

A mesa se corta em duas entre as duas parcelas. De um lado ficamos nós; do outro os parentes.

A pequena esposa do meu primo alto, o de boca molhada 
mo un pez y orejas de cera rebosante, viene hacia mí desde la otra mesa con gesto de arrojo (tras los cristales gruesos de sus lentes aparecen los ojos de indignación de muchacha provinciana que aún a pesar del encierro se hace temer, la de la lengua ácida). Se para frente a mí y me increpa: ¿por qué dijiste que mi tía es puta? Yo le digo: yo no dije nada, momentito.

Momentito: estoy recordando.

Hace veintisiete años dije algo. Dije, mirando la foto de la boda de la tía de la actual esposa de mi primo, dije: esta es una puta. Yo había aprendido la palabra puta y la usaba por vanidad. Mi vanidad se debía a haber aprendido a usar con ligereza algo que no parecía tan liviano.

La palabra. Esta es puta esta no es puta esta es puta. Yo no soy puta. Yo no soy una cualquiera.

Aunque sí, puede ser que lo haya dicho, mil perdones. Ella me mira y los ojos que veo son tan grandes, oh, qué grandes esos ojos que me miran detrás de los cristales engordados, cóncavos, amarillentos, y yo pienso que ya no son de ira esos ojos que ella tiene sino de tormento. Por qué esperar tanto tiempo para vengar a la tía puta, yo pienso. ¿Por qué me lo decís ahora, cuando ya pasó tanto tiempo? No demora, y dice, como si mordiera: Porque vos y tu madre y tu abuela tienen que tener un merecido. Yo sí demoro. ¿Un merecido por qué? Vuelve a morderme. No estar tan campantes, en esta mesa, cuando bien se sabe que son víboras. Me molesta más lo de campantes que lo de víboras. Yo no siempre salí ilesa de las críticas ajenas. Me cuido mucho de hacer- como um peixe e orelhas de cera transbordante, vem até mim da outra mesa com gesto de arrojo (atrás dos cristais grossos de suas lentes aparecem os olhos de indignação da moça provinciana que mesmo apesar do isolamento se faz temer, a da língua ácida). Para na minha frente e me repreende: por que disse que a minha tia é puta? Eu digo: eu não disse nada, momentinho. brando.

Momentinho: estou lem-

Há vinte e sete anos disse algo. Disse, olhando a fotografia do casamento da tia da atual esposa do meu primo, disse: esta é uma puta. Eu tinha aprendido a palavra puta e a usava por vaidade. Minha vaidade se devia a ter aprendido a usar com leveza algo que não parecia tão leve.

A palavra. Esta é puta esta não é puta esta é puta. Eu não sou puta. Eu não sou uma qualquer.

Apesar que sim, pode ser que eu tenha dito, mil perdões. Ela me olha e os olhos que vejo são tão grandes, oh, que grandes esses olhos que me olham atrás dos cristais engordados, côncavos, amarelentos, e eu penso que já não são de raiva esses olhos que ela tem mas de tormento. Por que esperar tanto tempo para vingar a tia puta, eu penso. Por que me diz agora, quando já passou tanto tempo? Não demora, e diz como se mordesse: porque você e sua mãe e sua avó tem que ter um castigo merecido. Eu sim demoro. E por que um castigo merecido? Volta a me morder. Não estar tão descaradas, nessa mesa, quando se sabe bem que são víboras. Me incomoda mais o descaradas que o víboras. Eu nem sempre saí ilesa das críticas alheias. Me cuido muito 
las, de decir: este es un vanidoso, aquella está llena de amargura. Es por eso que lo hablo más conmigo que con el resto y entonces me digo: qué vanidosos que estamos hoy, cuánta amargura me viene encima.

Dejo de prestarle atención a la esposa de mi primo el de la saliva y miro a una niña de rizos rojos que se ha venido a sentar a mi lado. La miro y no sé quién es, de qué pariente es hija. Se sienta como señorita entre mi hermana y yo; las dos la miramos con sorpresa. No nos pelea ni tampoco está jugando. Parece haber encontrado el lugar exacto para ella. Las piernitas le oscilan sin llegar al piso. Las mueve como si bailara, y noto unos minúsculos pelos rosados en las rodillas, en el borde de piel que queda libre entre las medias caladas y el organdí del traje. Rozo con mi dedo sus rodillas y ella se estremece y se ríe. Entonces me arrodillo y ella salta de la silla y nos ponemos a jugar bajo la mesa. Dice que se llama Olinka y que su nombre es ruso como el de algunas princesas. Jugamos a hacer caras de las feas y yo le gano. Afuera sigue el barullo, pero se oye apagado por el peso del mantel. Afuera alguien dice: nuestra ensalada es por lejos la mejor. Olinka se saca los zapatos y las medias caladas y me muestra su pie. Se lo huele y me lo da para que yo también lo huela. Lo huelo y le digo: ay, qué pie más asqueroso. Después vamos a los pies de la familia y se los olemos a todos. Algunos nos gustan y otros no. A ella le gustan más que a mí los pies de la familia. Los pies de mamá huelen rico. Tiene sandalias color café con tiras de cuero que se cruzan adelante. Mi hermana se rasca el ao fazê-las, de dizer: este é um vaidoso, aquela está cheia de amargura. É por isso que falo mais comigo disso que com os outros e então me digo: como estamos vaidosos hoje, quanta amargura me cai por cima!

Deixo de prestar atenção na esposa do meu primo o da saliva e olho uma menina de cachos vermelhos que vem sentar ao meu lado. Eu olho para ela e não sei quem é, de que parente é filha. Senta-se como senhorita entre minha irmã e eu; as duas a olhamos com surpresa. Não briga conosco e nem está brincando. Parece ter encontrado o lugar exato para ela. Suas perninhas oscilam sem chegar ao chão. Mexe-as como se dançasse, e noto uns minúsculos pelos rosados nos joelhos, na borda de pele que fica livre entre as meias caladas e o organdi do traje. Roço com meu dedo seus joelhos e ela se estremece e ri. Então me ajoelho e ela pula da cadeira e começamos a brincar embaixo da mesa. Diz que se chama Olinka e que seu nome é russo como o de algumas princesas. Brincamos de fazer caretas e eu ganho. Fora continua o barulho, mas se ouve apagado pelo peso da toalha. Fora alguém diz: nossa salada é de longe a melhor. Olinka tira os sapatos e as meias caladas e me mostra o seu pé. Cheira e me dá para que também o cheire. Cheiro e digo: ai, que pé mais nojento. Depois vamos aos pés da família e cheiramos todos. Gostamos de alguns de outros não. Ela gosta mais do que eu dos pés da família. Os pés de mamãe cheiram bem. Tem sandálias cor de café com tiras de couro que se cruzam na frente. Minha irmã coça o peito do pé com a ponta do 
empeine con la punta del zapato. Cuando acercamos las narices hace un movimiento brusco y le golpea el mentón a Olinka, que justo está oliendo. Olinka comienza a lloriquear y yo le tapo la boca con mi mano. En la mesa se hace silencio. Alguien ahoga una exclamación y se oye un zumbido.

Me acurruco entre las piernas estiradas de mi padre (sé que ahora yace satisfecho con la boca casi sonriente, plácida, y esos ojos de ausencia dichosa, de momento previo al desencanto) y atraigo a Olinka contra mi pecho como quien aprieta a un niño durante el estallido de una bomba.

La discusión entre las mesas da comienzo entonces.

\section{El tenista}

La cancha de tenis se esconde detrás de los pinos olorosos. Huelo los pinos desde mi escondite detrás de los troncos. Estoy enamorada del tenista. Es un muchacho con rodillas de piel traslúcida. La piel se le transparenta en las rodillas y entonces el hueso queda marcado como un puño apretado bajo un guante de látex. El triángulo de la rótula es delicado. Qué ósea la rodilla del muchacho. Cuánta belleza ósea.

Tiene medias deportivas $\mathrm{y}$ zapatos deportivos y short blanco y una remera blanca y el sol le deja el pecho resplandeciente y las piernas que corren a la derecha $y$ a la izquierda de la red van removiendo la tierra roja del piso hecho de motas de ladrillo. Qué material noble el ladrillo. sapato. Quando aproximamos os narizes faz um movimento brusco e atinge o queixo de Olinka que justamente está cheirando. Olinka começa a choramingar e eu tapo a sua boca com a mão. Na mesa se faz silêncio. Alguém afoga uma exclamação e se ouve um zumbido.

Encolho-me entre as pernas estiradas de meu pai (sei que agora jaz satisfeito com a boca quase sorridente, plácida, e esses olhos de ausência feliz, de momento prévio ao desencanto) e atraio Olinka contra meu peito como quem aperta uma criança durante a explosão de uma bomba.

A discussão entre as duas mesas tem começo então.

\section{O tenista}

A cancha de tênis se esconde atrás dos pinheiros perfumosos. Sinto o cheiro dos pinheiros no meu esconderijo atrás dos troncos. Estou apaixonada pelo tenista. É um rapaz com joelhos de pele translúcida. A pele fica transparente nos joelhos e então o osso está marcado como um punho apertado sob uma luva de látex. $\mathrm{O}$ triângulo da rótula é delicado. Que ósseo o joelho do rapaz. Quanta beleza óssea!

Tem meias esportivas e sapatos esportivos e short branco e uma camiseta branca e o sol deixa seu peito resplandecente e as pernas que correm para a direita e para a esquerda da rede vão removendo a terra vermelha do piso feito de pó de ladrilho. Que material nobre o ladrilho! 
Ese muchacho es una preciosura máxima con pelo negro que le cae sobre la frente en un mechón indómito. Siempre se dice mechón indómito. Qué hay de malo en que yo también diga si es lo que se dice: el mechón que cae, el indómito.

Los ojos siguen el trayecto de la pelota de tenis. No vale la pena decir cómo es esa pelota. Es una clásica pelota de tenis. Podría decirse que es una pelota que sigue el canon mundial de las pelotas de tenis. No se podría decir que la pelota sigue el cánon universal (porque sería atrevido: no sabemos qué ocurre en territorios de otros planetas) ni tampoco internacional, puesto que internacional no es tan inclusivo como mundial.

Los ojos de él son morenos y rasgados y las pestañas de él son largas y curvadas y la boca de él es la del capricho. Claro que estoy enamorada.

La contrincante es la enamorada del muchacho y no quiero detenerme en ella porque es mi rival. Sólo me detendría para decir que no me llega ni a los tobillos. Es más linda, sí. Y juega al tenis, y yo no sé jugar al tenis.

Y luego está lo de la exclamación de esfuerzo que ella profiere al momento de pegar a la pelota con el encordado de la raqueta. Es algo ciertamente erótico. Digo erótico con sorna.

Quién puede creer que esa breve exclamación más propia de un hachero que habita los montes nativos de la pampa que de una señorita pueda seducir a alguien. Nadie.
Esse rapaz é uma preciosidade máxima com cabelo preto que cai sobre a sua testa numa mecha indômita. Sempre se diz mecha indômita. Que mal faz que eu também diga se é o que se diz: a mecha que cai, a indômita.

Os olhos seguem o trajeto da bola de tênis. Não vale a pena dizer como é essa bola. É uma clássica bola de tênis. Poderia se dizer que é uma bola que segue o cânone mundial das bolas de tênis. Não se poderia dizer que a bola segue o cânone universal (porque seria atrevido: não sabemos o que acontece em territórios de outros planetas) nem tampouco internacional, posto que internacional não é tão inclusivo como mundial.

Os olhos dele são morenos e rasgados e as pestanas dele são compridas e curvadas e a boca dele é a do capricho. Claro que estou apaixonada.

A competidora é a namorada do rapaz e eu não quero me deter nela porque é minha rival. Só me deteria para dizer que não me chega nem aos pés. É mais bonita, sim. E joga tênis, e eu não sei jogar tênis.

E depois tem isso da exclamação de esforço que ela profere no momento de bater na bola com o encordoamento da raquete. É algo certamente erótico. Digo erótico com sorna.

Quem pode crer que essa breve exclamação mais própria de um lenhador que habita os montes nativos dos pampas que de uma senhorita possa seduzir alguém. Ninguém. 
Tradução de Helena Coimbra Meneghello \& Rosario Lázaro Igoa
helenacm@terra.com.br / rosilazaro@gmail.com
Universidade Federal de Santa Catarina

Fonte: Inés Bortagaray. "A la mesa”, in Revista N. Suplemento cultural Diario Clarín. Buenos Aires, 14 de agosto de 2010. pp. 28.

"El tenista", inédito.

\section{Comentarios sobre la traducción}

En el año 2009, la revista Zoetrope: All-story, templo norteamericano del cuento breve, publicó "A la mesa", de la autora uruguaya Inés Bortagaray. La edición estaba enfocada a Latinoamérica, y contaba con historias de otros cuentistas jóvenes, y dibujos del cineasta Guillermo del Toro. Al respecto, una nota en El País de Madrid indicaba: "Las miradas vuelven a buscar el continente. Pero no encontrarán el tan profetizado nuevo boom, sino el redescubrimiento pausado y normalizado de un territorio narrativo cuyo talento y calidad de temas y estilos nada tienen que envidiar a lo creado en otros países o continentes." (MANRIQUE SABOGAL, 2009). Un año más tarde, dando una vuelta de retorno al Río de la Plata, la Revista Ñ del diario argentino Clarín, publicó “A la mesa" nuevamente el 14 de agosto de 2010.

No es nuevo que el espacio editorial uruguayo es reducido y depende de otros para su visibilidad. Configurado por su pertenencia al espacio del Río de Plata, comparte con Argentina, y más precisamente con Buenos Aires, algunos denominadores comunes, y precisa la mayoría de las veces del impulso de sus vecinos bonaerenses para la consagración de los escritores orientales. En los últimos años, el reconocimiento argentino a Marosa di Giorgio (1932-2004), o la devoción para con las obras de Mario Levrero (1940-2004) -por nombrar a dos de los "raros" como los llamara Rama (RAMA, 1966) siguiendo el adjetivo de Rubén Darío- así lo demuestran. Sin embargo, la difusión de estas voces ocurre en ambas orillas, y en ocasiones en los EEUU. El pasaje por Brasil es muchas veces obviado, y resultado de ello es la mínima difusión que tienen los autores uruguayos contemporáneos en las tierras brasileñas (lo inverso también ocurre, pero por razones que creemos distintas).

Inés Bortagaray nació en Salto, la tierra de Marosa y Quiroga, en 1975. $\mathrm{Su}$ primer libro, dentro de la colección De los flexes Terpines, dirigida por Mario Levrero, se llamó Ahora tendré que matarte (Cauce, 2001). Cinco años más tarde, publicó Prontos, listos, ya (Artefato, 2006) un relato de un largo viaje de una familia hacia la playa, contado desde la perspectiva de una niña, novela que fue luego reeditada en 2010 en Caracas, por la editorial sudamericana Punto Cero. 
Para definir el estilo de Bortagaray es oportuno precisar su ligación con Mario Levrero, con quien talleres de motivación literaria. En cierta forma, la afinidad entre una y otra prosa creemos que se da en el plano de la expresión de la subjetividad, y las referencias autobiográficas, notas características sobre todo del último período de Levrero, y muy especialmente de La novela luminosa (2005), y no tanto de novelas como las de la "trilogía involuntaria" La ciudad, París y El lugar, donde: "tienen lugar travesías de sujetos que manifiestan una inadecuación con una realidad entre onírica y carcelaria, que remeda a la que se construye en ciertos textos de Kafka" (MONTOYA JUÁREZ, 2008: 210).

Ya Rama delineaba en 1966 algunos de los rasgos que consideramos que Levrero comparte con Bortagaray, como ser el privilegio de la imaginación, y "un uso riquísimo de la afectividad, un hallazgo constante de nuevos matices de la sensibilidad" (RAMA, 1966: 12). En este mismo sentido, Jorge Olivera, afirma: "La historia de la literatura uruguaya tiene dos líneas narrativas claras que la recorren: una, cuyos componentes son los propios de un realismo crítico; y otra, secreta y marginal, de corte imaginativo. Estas dos tendencias se extienden desde el siglo XIX hasta el presente." (OLIVERA: 2005, 43). Otro tanto lo expresan las palabras de José Gabriel Lagos, coeditor de la sección cultura de La Diaria, quien definió a una generación que posee el rasgo común de "la concurrencia o afinidad con el taller que dirigía Mario Levrero, aunque sus obras no tengan grandes similitudes con la de este escritor", y cuyos relatos poseen rasgos como: "primerísima persona, limitados por micromundos personales, y muy breves (sus libros raramente llegan a las 100 páginas)" (In: MICHELINI, 2007).

Otra línea en común entre Levrero y Bortagaray podrían ser intensa visualidad de la prosa, con un registro exhaustivo de los detalles. Es cierto que este aspecto fue promovido por Levrero en sus talleres, donde proponía casi que excluyentemente la escritura desde la primera persona, el trabajo a partir de anécdotas puntuales y cotidianas, un registro verosímil por medio de los elementos visuales, y la acción como resultado del registro perceptivo de tales anécdotas. Sin embargo, creemos en la singularidad de la prosa de la escritora, en tanto introduce asimismo una visión personal muy aguda y expresiva, jugando casi en la tensión de un mundo infantil con otro de las palabras de los adultos.

La ausencia de estudios académicos sistemáticos sobre la obra de esta generación incipiente, y también la falta de una distancia crítica que permita entrever sus obras con el filtro del tiempo, no parecen sin embargo impedimento para su difusión entre una y otra lengua. En la traducción de estos dos cuentos, nos mueve el afán de difundir una autora de las letras uruguayas contemporáneas, y la valoración que hacemos del interés de sus escritos.

Los dos cuentos elegidos, "A la mesa" y "El tenista" (inédito), poseen varios puntos en común. En primer lugar, son breves y están escritos desde la reiterada primera persona que utiliza la autora, la "primerísima" a decir de Lagos, dando cuenta de un punto de vista ingenuo, casi "naif" de la realidad que la circunda. En "A la mesa", la historia gira en torno a un almuerzo familiar, retratado por la inquisitiva visión de la protagonista, que tiene un altercado con la esposa de su primo, y luego olvida rápidamente el mismo cuando una niña viene a sentarse a su lado. Lo interesante es cómo gradualmente la acción se desplaza a debajo de la mesa, el tiempo en cierta forma se suspende con los juegos de la protagonista y la niña, mientras se retoman las peleas familiares. Detalles como: 
"y noto unos minúsculos pelos rosados en las rodillas, en el borde de piel que queda libre entre las medias caladas y el organdí del traje", evidencian un certero sentido de la observación, en una prosa repleta de detalles aparentemente intrascendentes, pero que son los que justamente en su conjunto de humor e imprevisibilidad le otorgan el signo característico a la prosa de Bortagaray.

Ya "El tenista", relato ingenuamente erótico, si se puede denominar así, la protagonista observa a un muchacho desde un escondite entre los pinos, y realiza conjeturas sobre los sentimientos que siente hacia él. Se repiten precisas descripciones, como: "La piel se le transparenta en las rodillas y entonces el hueso queda marcado como un puño apretado bajo un guante de látex", que le otorgan una visualidad muy marcada a los relatos. Nuevamente, no hay demasiada acción en este relato, pero sí un detenimiento sobre aspectos secundarios, observaciones agudas, frases irónicas, y hasta juegos de palabras casi burdos, como los que siguen: "No se podría decir que la pelota sigue el cánon universal (porque sería atrevido: no sabemos qué ocurre en territorios de otros planetas) ni tampoco internacional, puesto que internacional no es tan inclusivo como mundial.".

Si bien en la tarea de traducción no antepusimos presupuestos teóricos, es verdad que nos orientó la voluntad de recrear los textos en portugués brasileño, así como el de mantener las principales características de la prosa de Bortagaray en la lengua de llegada. En este punto, usamos el concepto de traducción de acuerdo a la letra, que Antoine Berman propuso en La traduction et la lettre (1999), en tanto indica: "la traduction est traduction-de-la-lettre, du texte en tant qu'il est lettre" (BERMAN, 1999:8), donde el teórico francés propone aceptar las tensiones propias entre las lenguas y no tratar de mitigarlas ni desdibujarlas, sino hacerlas evidentes. En este sentido, y aunque ambos objetivos pueden parecer contrapuestos, tratamos de "tensar" al máximo la capacidad del portugués de ofrecer soluciones a la aparente similitud del español, teniendo como límite, claro está, la comprensión del texto por parte de su posible lector en portugués.

Para comentar algunos aspectos de la traducción que fueron comunes a ambos textos, trabajaremos con ambos cuentos en conjunto, y destacaremos las soluciones adoptadas en cada caso.

Una de las principales dificultades que encontramos, derivada del uso de la primera persona y de la intimidad con que la narradora se dirige al lector, es la proliferación, ya de por sí marcada en el español, de los pronombres personales átonos. Buscando no elevar el registro de la prosa de Bortagaray, decidimos mantener los mismos cuando fuera necesario, pero omitirlos cuando el uso informal del portugués brasileño así lo indicara. Por ejemplo, en la traducción de "A la mesa", que titulamos como "À mesa", hay un ejemplo paradigmático de lo anterior:

Se lo huele y me lo da para que yo también lo huela. Lo huelo y le digo: ay, qué pie más asqueroso.
Cheira e me dá para que também o cheire. Cheiro e digo: ai que pé mais nojento.

En cuanto a las soluciones dentro del campo fonético, que si bien no constituyen una línea de exploración deliberada del texto, sí encontramos algunos fragmentos donde las aliteraciones tienen especial valor, como en el ejemplo que sigue de "A la mesa", donde se desplazaron dentro del sintagma en el texto en portugués: 
Sobre el mantel hay platos, fuentes, cucharas, cucharones, cuchillos, servilletas, tenedores, botellas, jarras, flores, migas de pan.
Sobre a toalha há pratos, travessas, colheres, conchas, facas, guardanapos, garfos, garrafas, jarras, flores, miolo de pão.

La aliteración más marcada del fragmento en español, dada por la repetición de la sílaba "cu" de "cucharas, cucharones, cuchillos", que otorga la idea de aglomeración, se desplaza a una reiteración de la sílaba "co" en portugués ("colheres, conchas"), menos evidente, pero se retoma con la repetición de la consonante "g", y luego la vocal "a" asociada: "guardanapos, garfos, garrafas, jarras". Es destacable que aunque se detecta la pérdida de la aliteración del original, se rescata por medio de otra próxima en el sintagma en cuestión.

A nivel lexical, es interesante destacar el uso de las palabras fuera de su uso habitual, palabras de un registro más elevado dentro de una prosa informal e intimista. Por ejemplo, en "El tenista" se lee "gesto de arrojo", una expresión no tan usual en el español rioplatense, que decidimos traducir literalmente ("gesto de arrojo"). Ciertas colocaciones como: "ojos de ausencia dichosa", se traducen por "olhos de ausência feliz". En cuanto a la traducción de "Muchacho" por "rapaz", y no "moço". La extrañeza del sustantivo "sorna", lo mantuvimos, interpretándolo en el original como pereza, pero también con cierto contenido irónico, significados que el Diccionario RAE: "1. f. Espacio o lentitud con que se hace algo./2. f. Disimulo y bellaquería con que se hace o se dice algo con alguna tardanza voluntaria./3. f. ironía". Se traduce así de acuerdo también a los significados del Diccionario Michaelis: "1 Diz-se da, ou a pessoa indolente, inerte, preguiçosa. 2 Diz-se de, ou aquele que é maçador, impertinente, aborrecido. sf 1 Indolência, inércia. 2 Soneca. 3 gír Aborrecimento, maçada.”. Asimismo, creemos que se logra reproducir la extrañeza de esa palabra, en ambos idiomas.

Otra de las características de la prosa de Inés es una cierta, e irónica, reflexión sobre la palabra en sí, sobre el significado de algunos términos extraños que se deslizan por su prosa. También allí están las reiteraciones de palabras, que ambos textos presentan. Como resultado, tratamos de trabajar especialmente sobre tales términos, para que no perdieran la agudeza del humor implícito, mientras la sintaxis se asemeja en cierta forma a la oralidad, como en estos pasajes de "A la mesa":

Yo le digo: yo no dije nada, momentito.

Momentito: estoy recordando.
Eu digo: eu não disse nada, momentinho.

Momentinho: estou lembrando. cales, fue:

Otro ejemplo de lo anterior, que no presentó mayores dificultades lexi-

La palabra. Esta es puta esta no es puta esta es puta. Yo no soy puta. Yo no soy una cualquiera.
A palavra. Esta é puta esta não é puta esta é puta. Eu não sou puta. Eu não sou uma qualquer.

Aquí se nos presentó la duda de con qué palabras poder transmitir la cierta "inocencia" del cuento al usar un adjetivo como "campantes": 
No estar tan campantes, en esta mesa, cuando bien se sabe que son víboras. Me molesta más lo de campantes que lo de víboras.
Não estar tão descaradas, nessa mesa, quando se sabe bem que são víboras. Me incomoda mais o descaradas que o víboras.

Como vimos, en "El tenista", encontramos la misma tendencia, cuando expresa: "Es algo ciertamente erótico. Digo erótico con sorna."

Como último comentario, queremos presentar un problema relacionado a los pronombres interrogativos y exclamativos. En español los mismos son tónicos, y se diferencian así de los pronombres relativos, lo que no ocurre en portugués, idioma en el que presentan la misma forma. La forma de la prosa de Bortagaray los incluye de una forma particular, pues no acompaña al grupo sintáctico de signos de exclamación o interrogación, sino que los asimila al ritmo de la narración, como en: "qué vanidosos que estamos hoy, cuánta amargura me viene encima". Frente a ello, decidimos realizar el añadido de tales signos en la traducción, siempre que su incorporación no interfiriera en la consecución sintáctica de las oraciones. Los casos en los que agregamos los signos de exclamación son:

Cuánta belleza ósea.

Qué material noble el ladrillo. qué vanidosos que estamos hoy, cuánta amargura me viene encima.
Quanta beleza óssea!

Que material nobre o ladrilho! como estamos vaidosos hoje, quanta amargura me cai por cima!

Sin embargo, en los casos que siguen privilegiamos el encadenamiento de las oraciones tal como se presentan en el original, donde la introducción de los signos de exclamación podría interferir en demasía:

oh, qué grandes esos ojos que me miran detrás de los cristales engordados, cóncavos, amarillentos, y yo pienso que ya no son de ira esos ojos que ella tiene sino de tormento. oh, que grandes esses olhos que me olham atrás dos cristais engordados, côncavos, amarelentos, e eu penso que já não são de raiva esses olhos que ela tem mas de tormento.

Lo mismo ocurrió con el pronombre interrogativo "quién" del ejemplo que sigue, que para la traducción consideramos que la oración que le sigue ('Nadie"), provee información que no deja dudas al respecto de su función interrogativa en portugués:

Quién puede creer que esa breve exclamación más propia de un hachero que habita los montes nativos de la pampa que de una señorita pueda seducir a alguien. Nadie.
Quem pode crer que essa breve exclamação mais própria de um lenhador que habita os montes nativos dos pampas que de uma senhorita possa seduzir alguém. Ninguém.

Para terminar, y al margen de otros comentarios que puedan seguir surgiendo con más lecturas sobre aspectos múltiples, consideramos de gran interés la complementariedad de un enfoque de una hablante nativa del portugués brasileño, y una hablante nativa del español, para la traducción de estos dos cuentos. Asimismo, contamos con el aporte de la autora para dudas puntuales, lo que enriqueció el proceso de verter los cuentos entre lenguas tan cercanas, pero tan 
distintas al mismo tiempo, y no tan comunicadas entre sí en el plano de la narrativa contemporánea.

\section{Helena Coimbra Meneghello \& Rosario Lázaro Igoa helenacm@terra.com.br/rosilazaro@gmail.com \\ Universidade Federal de Santa Catarina}

\section{Referências bibliográficas}

Berman, Antoine. La traduction et la lettre, ou L'auberge du lointain. Paris: Seuil, 1999.

Bortagaray, Inés. Ahora tendré que matarte. Colección De los flexes terpines. Montevideo: Cauce, 2001.

. Prontos, listos, ya. Montevideo: Artefato, 2006.

. "At the table". In: Zoetrope: All-story. The Latin American Issue. Vol

13 No 1. Spring 2009.

DICCIONARIO RAE. Versión digital: http://www.rae.es/rae.html

DICCIONARIO MICHAELIS. Versión digital: http://michaelis.uol.com.br/

MichelinI, Margarita. "Los jóvenes escritores se ven interesantes". In: Cosas de la vida. 2007. Disponible en:

http://www.cosasdelavida.com/index.php?option=com_content\&task=view\&id $=26$ Acceso en: 25 de marzo de 2011 .

MANRIQUE SABOGAL, Winston. "En el umbral de nuevos mundos". In: El País. 09/05/2009. Disponible en:

http://www.elpais.com/articulo/semana/umbral/nuevos/mundos/elpepuculbab/2 0090509elpbabese_9/Tes Acceso en: 27 de marzo de 2011.

OliverA, Jorge. "El miedo en la literatura uruguaya: un efecto de construcción narrativa". In: Anales de Literatura Hispanoamericana. 2005, 34. Pp. 43-69

Rama, Ángel. Aquí. Cien años de raros. Montevideo: Arca, 1966. . La generación crítica. Montevideo: Arca. 1972. 